\title{
Kreps, David M.: Microeconomics for managers
}

\section{Second edition, Princeton University Press, Woodstock, UK, 2019, $520 \mathrm{pp}$, Hardcover, $£ 30.00$}

\section{Preface to the Second Edition}

Part I: the economics of relationships

1. The economics of relationships (and Porter's five forces)

2. Noncooperative game theory

3. Reciprocity and collusion

4. Credibility and reputation

5. Transaction-cost economics

Part II: pricing with market power

6. Marginal cost equals marginal revenue

7. Mark-up pricing and elasticity

8. Price discrimination

9. Channels of distribution and double marginalization

Part III: Bang for the buck: optimization under constraint

10. The utility-maximizing consumer

11. Technology and cost minimization

12. Multiperiod production and cost

Part IV: competitive markets

13. The most famous picture in economics

14. Competitive firms in competitive markets

15. The invisible hand

16. Taxes, subsidies, administered prices, and quotas

17. Externalities

Part V: uncertainty and information

18. The expected-utility model

19. Risk sharing and spreading: securities and insurance markets

20. Hidden information: adverse selection, signaling, and screening

21. Hidden action: moral hazard and incentives

Index

Publisher's Note Springer Nature remains neutral with regard to jurisdictional claims in published maps and institutional affiliations 